УДК 681.518 .5

https://doi.org/10.36906/AP-2020/42

\title{
ПРОГРАММНОЕ ОБЕСПЕЧЕНИЕ УСТРОЙСТВА УПРАВЛЕНИЯ ДОПОЛНИТЕЛЬНОЙ НАГРУЗКОЙ ДЛЯ СИСТЕМЫ ДИАГНОСТИКИ ЛИТИЕВЫХ АККУМУЛЯТОРОВ ПО РЕЛАКСАЦИОННЫМ ПРОЦЕССАМ
}

Енилиев Р. P.

Казанский национальный исследовательский технический университет им. А.Н. Туполева

2. Казань, Россия

Никишина Г. В.

Казанский национальный исследовательский технический университет им. А.Н. Туполева

2. Казань, Россия

Денисов Е. С.

канд. техн. наук

Казанский национальный исследовательский технический университет им. А.Н. Туполева

2. Казань, Россия

Аннотация. В работе предложено программно-аппаратное обеспечение устройства управления нагрузкой для реализации систем диагностики электрохимических источников тока на основе анализа релаксационных процессов. Соответствующие системы диагностики предназначены для использования в перспективных электронных и робототехнических системах с автономным питанием.

Ключевые слова: литиевые аккумуляторы; технический контроль, программноаппаратные системы, электрохимические источники тока, релаксационные процессы, устройство управления нагрузкой.

Научные исследования проведены при финансовой поддержке Минобрнауки России в рамках исполнения обязательств по Соглашению номер 075-03-2020-051 (номер темь fzsu2020-0020)

Широкое распространение литиевых аккумуляторов в современной портативной электронике и робототехнике требует развития и внедрения новых эффективных средств их технического контроля. Существующие методы контроля либо имеют малую информативность, либо требуют дорогостоящего технически сложного оборудования. Например, стоимость лабораторных импедансметров достигает нескольких десятков тысяч долларов. К тому же продолжительность измерения импеданса может составлять несколько минут и даже десятков минут, то есть за это время состояние аккумулятора может существенно измениться, например, за счет его разряда. В работах $[1,3]$ показано, что для диагностики технического состояния может использоваться переходная характеристика, вызванная скачкообразным изменением тока нагрузки. Однако этот метод имеет недостаток, связанный со сложностью формирования скачкообразного изменения тока нагрузки, из-за высокой емкости аккумуляторов. В работе [2] предложено заменить скачок тока нагрузки на 


\section{СОВРЕМЕННОЕ ПРОГРАММИРОВАНИЕ}

III Международная научно-практическая конференция

скачок сопротивления нагрузки, такой метод требует более сложной математической обработки результатов измерений, однако, может быть реализован на простом, малогабаритном и недорогом измерительном оборудовании. Данный метод требует специализированных программно-аппаратных средств. Вопросам реализации модуля управления дополнительной нагрузкой посвящена данная работа.

Согласно методу диагностики на основе анализа релаксационных процессов, вызванных естественными или искусственными флуктуациями нагрузки, требуется реализовать устройство, позволяющее коммутировать дополнительную нагрузку параллельно основной. При этом на устройство накладываются следующие требования: обеспечение коммутации нагрузки с заданными временными интервалами, управление от персонального компьютера и возможность полного отключения нагрузки от аккумулятора для его защиты от избыточного разряда.

Функциональная схема системы для реализации метода диагностики литиевых аккумуляторов по естественным или вынужденным изменениям нагрузки представлена на рис. 1. Здесь мы можем выделить контролируемый литиевый аккумулятор, его основную нагрузку, подключенную через реле $\mathrm{K} 1$ для обеспечения возможности защитного отключения аккумулятора. Параллельно основной нагрузке посредством реле К2 коммутируется дополнительная нагрузка $\Delta \mathrm{R}_{\mathrm{H}}$. Управлениие обоими реле осуществляется микропроцессорной системой Arduino. Кроме этого в систему входит персональный компьютер для осуществления обработки данных и выработки управляющих сигналов на основе информации о токе генерируемом аккумулятором и напряжении на нагрузке, обеспечиваемой аналого-цифровым преобразователем (АЦП). При обнаружении критически низкого напряжения на нагрузке литиевого аккумулятора персональный компьютер формирует сигнал защитного отключения.

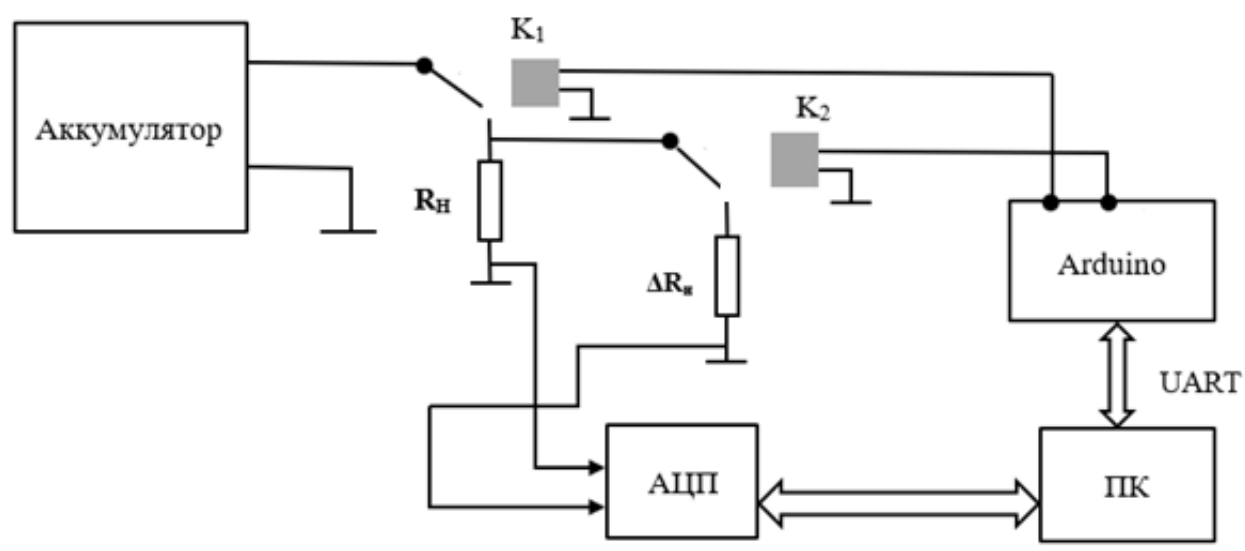

Рис. 1. Функциональная схема системы контроля технического состояния литиевого аккумулятора: $\mathrm{K}_{1}$ - реле 1 ; $\mathrm{K}_{2}$-реле 2 ; $\mathrm{RH}_{\mathrm{H}}$ - основная нагрузка; $\Delta \mathrm{RH}$ - дополнительная нагрузка; АЦП - аналогово-цифровой преобразователь; ПК - персональный компьютер; UART - универсальный асинхронный приемопередатчик

Алгоритм работы устройства управления дополнительной нагрузкой представлен на рисунке 2. Алгоритм включает в себя следующие этапы:

1. прием от персонального компьютера установок о временных параметрах процесса коммутации дополнительной нагрузки;

2. прием команды начала измерений, при котором замыкается реле К1 и начинается процесс коммутации дополнительной нагрузки;

3. определение времени переключения дополнительной нагрузки; 


\section{СОВРЕМЕННОЕ ПРОГРАММИРОВАНИЕ}

III Международная научно-практическая конференция

4. проверка достижения заданного интервала времени с момента последнего переключения (если не достигнуто переходим к п.5, иначе к п. 9);

5. определение текущего момента времени;

6. проверка наличия команды остановки (если есть, то переходим к п. 7, иначе к п. 4);

7. отключение всех реле;

8. остановка программы;

9. переключение реле К2 и переход к п. 3.

Для исследования программно-аппаратного обеспечения устройства управления дополнительной нагрузкой было проведено его моделирование в среде Tinkercad. В процессе моделирования были использованы следующие модели: аккумулятор 9В, микропроцесорная система Arduino Uno R3, макетная плата, два однополюсных реле, а также два резистора в качестве модели основной и дополнительной нагрузок. С помощью микропроцессорной системы Arduino приводились в действие реле, коммутирующие нагрузку. Одно реле, подключенное ко входу D13 Arduino, коммутировало основную нагрузку, а другое, подключенное к D11, коммутировало дополнительную. Использование функции millis() и введенной переменной timing в программном коде позволило включать/отключать реле, коммутирующее основную нагрузку через заданные интервалы времени. Для обмена информацией с персональным компьютером использовался последовательный порт, сконфигурированный для передачи данных со скоростью 9600 бод. Управление коммутацией основной и дополнительной нагрузок осуществлялось посредством отправки персональным компьютером команд «Стоп», «Вкл.» и «Выкл.».

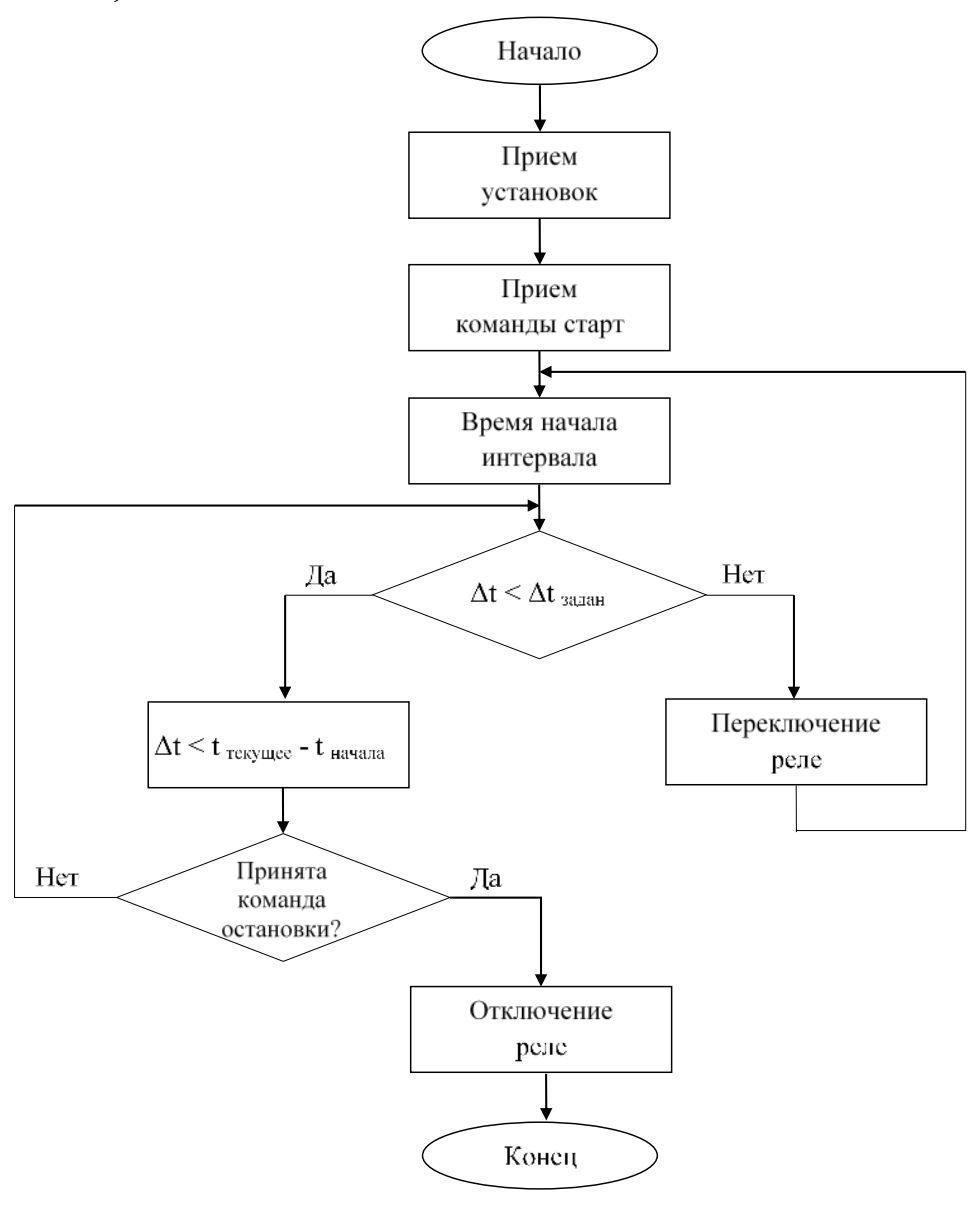

Рис. 2. Алгоритм работы устройства управления дополнительной нагрузки 


\section{СОВРЕМЕННОЕ ПРОГРАММИРОВАНИЕ}

III Международная научно-практическая конференция

Проведенное в среде Tinkercad моделирование показало корректность предложенного программно-аппаратного обеспечения устройства управления дополнительной нагрузкой.

Предлагается устройство управления дополнительной нагрузкой для исследования и практической реализации перспективных методов и средств диагностики литиевых аккумуляторов по переходным характеристикам, вызванным изменением нагрузки, на основе микропроцессорной системы Arduino и электромагнитных реле. Соответствующие методы и средства диагностики могут найти применение в электронных и робототехнических системах с автономным питанием.

\section{Литература}

1. Denisov E. et al. Lithium battery transient response as a diagnostic tool // Journal of Electronic Materials. 2018. Vol. 47. №8. P. 4493-4501. https://doi.org/10.1007/s11664-018-6346-y

2. Denisov E., Nikishina G., Demidov A. Electrochemical Power Sources Relaxations Related with Step-like Load Variation // 2020 Ural Symposium on Biomedical Engineering, Radioelectronics and Information Technology (USBEREIT). IEEE, 2020. P. 230-233. https://doi.org/10.1109/USBEREIT48449.2020.9117665

3. Тимергалина Г. В., Никишин Т. П. Оценка возможности диагностики электрохимических источников тока по переходным характеристикам // XXIII Туполевские чтения (школа молодых ученых): Международная молодежная научная конференция: материалы конференции. 2017. С. 717-720.

(СЕнилиев Р. Р., Никишина Г. В., Денисов Е. С., 2020 